\title{
VHF volume-imaging radar observation of aspect-sensitive scatterers tilted in mountain waves above a convective boundary layer
}

\author{
R. M. Worthington ${ }^{1,2,3}$ \\ ${ }^{1}$ Institute of Mathematical and Physical Sciences, University of Wales, Aberystwyth, SY23 3BZ, UK \\ ${ }^{2}$ Radio Science Center for Space and Atmosphere (RASC), Kyoto University, Uji, Kyoto 611-0011, Japan \\ ${ }^{3}$ School of Earth, Atmospheric and Environmental Sciences, Univ. of Manchester, P.O. Box 88, Manchester, M60 1QD, UK
}

Received: 13 August 2004 - Revised: 15 March 2005 - Accepted: 22 March 2005 - Published: 3 June 2005

\begin{abstract}
Thin stable atmospheric layers cause VHF radars to receive increased echo power from near zenith. Layers can be tilted from horizontal, for instance by gravity waves, and the direction of VHF "glinting" is measurable by spatial domain interferometry or many-beam Doppler beam swinging (DBS). This paper uses the Middle and Upper atmosphere (MU) radar, Shigaraki, Japan as a volume-imaging radar with 64-beam DBS, to show tilting of layers and air flow in mountain waves. Tilt of aspect-sensitive echo power from horizontal is nearly parallel to air flow, as assumed in earlier measurements of mountain-wave alignment. Vertical-wind measurements are self-consistent from different beam zenith angles, despite the combined effects of aspect sensitivity and horizontal-wind gradients.
\end{abstract}

Keywords. Meteorology and atmospheric dynamics (Convective processes; Waves and tides). Radio science (Instruments and techniques)

\section{Introduction}

Echo power of VHF atmospheric radar is often increased in beams pointing near zenith ("aspect sensitivity"), because of thin stable layers or anisotropic turbulence. The diffuse glinting pattern of VHF echo power can also be tilted from zenith, when atmospheric layers are tilted from horizontal (Gage et al. 1981; Tsuda et al. 1997; Worthington 1999a), for instance by mountain waves.

Since VHF aspect-sensitivity is caused by atmospheric stability layered on vertical scale $\sim 3 \mathrm{~m}$, which is typically less than $\sim 0.2 \%$ of mountain-wave vertical wavelengths, thin glinting layers could act as tracer of air flow through a wave pattern, without modifying the waves. Isotropic echo power

Correspondence to: R. M. Worthington

(rmw092001@yahoo.com) has been assumed a tracer, showing streamlines of air flow tilted from horizontal in mountain waves (Starr and Browning 1972). However, it is unclear if thin stable layers similarly follow the streamlines of mountain-wave airflow, which is an assumption for measurements of mountain-wave alignment and launching height (Worthington 1999a,b, 2002). Vertical shear of horizontal wind also can cause skewing of the echo power pattern (Worthington and Thomas 1996; Yamamoto et al. 2003; Hirono et al. 2004).

This paper uses a simple DBS (Doppler beam swinging) method of volume-imaging, to measure the tilting of VHF glinting patterns in three dimensions, and check if thin stable layers remain parallel to air flow in mountain waves (Worthington 1999a,b, 2002). Figure 1 shows the MU radar in a 64-beam DBS mode; 63 beams are plotted since there is a duplicate vertical. The beam transmitted by the entire radar array switches direction every $400 \mu \mathrm{s}$ to volume-image the atmosphere, with range resolution $150 \mathrm{~m}$ and transmitted beamwidth $3.6^{\circ}$. Measurement time is 64 beams $\times 400 \mu \mathrm{s}$ inter-pulse-period $\times 1$ incoherent integration $\times 2$ coherent integrations $\times 128$ FFT points $=6.55 \mathrm{~s}$. The MU radar mode is identical to 15-16 July 2002 in Worthington (2004). Volumeimaging refers only to three-dimensional measurement of atmosphere, not e.g. multiple-frequency or multiple-receiver radar interferometric methods. For routine long-term measurements of mountain-wave alignment, 5-beam data may be more practical than many-beam data, due to lesser requirements for transmitter power, computer processing and file storage. However, 5-beam measurements use significant assumptions, which are checked for the first time in this paper using many-beam data.

\section{Observations}

Figure 2 shows height-time plots, 07:43 JST 12 December - 00:04 JST, 13 December 2002, for $\sim 1-5 \mathrm{~km}$ AGL (above 


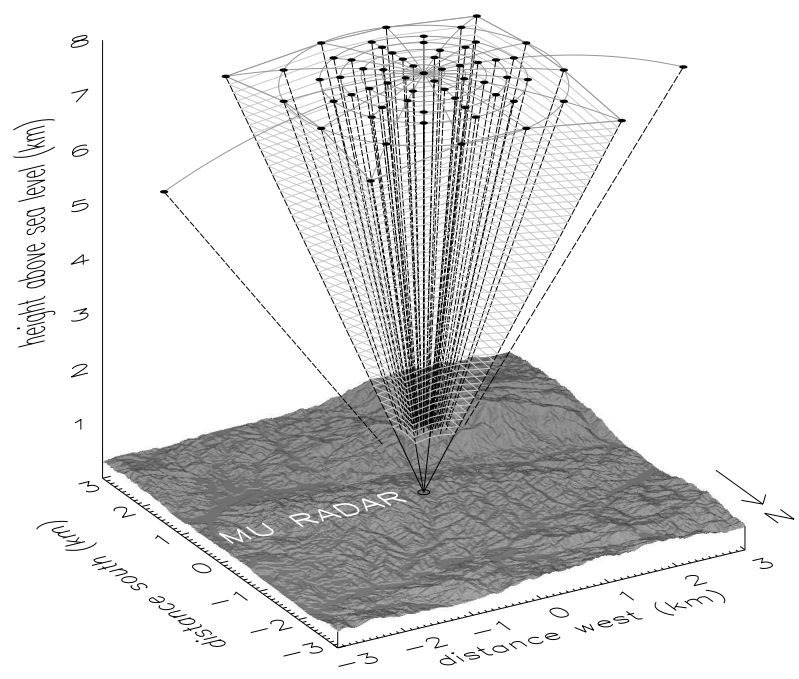

Fig. 1. Three-dimensional view of the $\mathrm{MU}$ radar $\left(34.85^{\circ} \mathrm{N}\right.$, $136.10^{\circ} \mathrm{E}$ ) in a volume-imaging mode with 64 beams at $0^{\circ}, 2^{\circ}, 4^{\circ}$, $6^{\circ}, 8^{\circ}, 10^{\circ}, 14^{\circ}, 20^{\circ}, 30^{\circ}$ from zenith. Dots are beam directions, dashed lines are 150-m range gates, grey lines are at constant range from the radar, with circular grey lines at constant zenith angle, and shaded surface is land height. Azimuth separation of the grey lines across zenith is $15^{\circ}$.

ground level) where there is significant echo power, Fig. 2a, and aspect sensitivity, Fig. 2b. Japan Standard Time (JST) is UTC $+9 \mathrm{~h}$. Vertical wind $(W)$ is measured using vertical beam, Fig. 2c, and symmetric pairs of beams $10^{\circ}$ off zenith, Fig. 2 d e.g. $W_{10}=\frac{1}{2}\left(v_{\mathrm{n}}+v_{\mathrm{s}}\right) / \cos 10^{\circ}$ or $\frac{1}{2}\left(v_{\mathrm{e}}+v_{\mathrm{W}}\right) / \cos 10^{\circ}$ or $\frac{1}{4}\left(v_{\mathrm{n}}+v_{\mathrm{s}}+v_{\mathrm{e}}+v_{\mathrm{w}}\right) / \cos 10^{\circ}$ where $v_{\mathrm{n}}, v_{\mathrm{s}}, v_{\mathrm{e}}, v_{\mathrm{w}}$ are lineof-sight velocities in beams $10^{\circ}$ off zenith toward north, south, east and west.

Non-zero $W$ measured by MU radar has been attributed to heirarchical structures of cyclones (Shibagaki et al. 1997) and jet stream circulations (Takayabu et al. 2000). However, $W$ as in Figs. 2c and $\mathrm{d}-$ tens of $\mathrm{cm} \mathrm{s}^{-1}$ and slowly varying over many hours - is consistent with mountain waves (Sato 1990) or convection waves in summer (Sato 1992) above the mountains surrounding the MU radar, and mountain waves can be very similar to convection waves (Worthington 2002). Figure 2 is measured in winter, Fig. 3d showing surface temperature $\sim 0-5^{\circ} \mathrm{C}$ and no diurnal, convective variation of surface wind speed or variance as in e.g. Fig. 3c of Worthington (2004). Nevertheless, radiosondes show a convective boundary layer to $\sim 1.3 \mathrm{~km}$ AGL in Figs. $3 \mathrm{a}$ and b, inferred from near-adiabatic lapse rate and high humidity below temperature inversions and lower humidity ${ }^{1}$. Also, moving echo-power patterns in Fig. $4 \mathrm{~b}$ are similar in appearance to those in cloud or convection, Figs. 5 and 6 of Worthington (2004). Figures $2 \mathrm{c}$ and d show little phase variation of $W$ with height, as if vertical wavelength is many kilometres

\footnotetext{
${ }^{1}$ In Fig. 4a of Worthington (2004), radiosonde heights are above sea level instead of ground level, and should be shifted down $\sim 0.4 \mathrm{~km}$ for comparison with radar heights.
}

or infinite since mountain waves are trapped. Brunt-Väisälä frequency is non-zero above $\sim 1 \mathrm{~km}$ in Fig. 3 and horizontal wind speed increases rapidly with height, implying Scorer parameter decreasing with height, consistent with mountain waves trapped above the convective boundary layer.

Mountain waves tilt air flow and also aspect-sensitive layers from horizontal, shown by imbalances of echo power using 5-beam radar (Worthington, 1999a). Tilt of the aspectsensitivity pattern can be measured using spatial domain interferometry (Hobbs et al. 2000) or many-beam DBS (Palmer et al. 1998). Figures $2 \mathrm{e}$ and $\mathrm{f}$ show tilt from zenith, from a weighted mean of echo power above isotropic level (e.g. beams shown as red dots in Fig. 4 a, with mean tilt as blue $\times$, for 100 of 8981 volume images), using beams $0^{\circ}-6^{\circ}$ from zenith, although $0^{\circ}-8^{\circ}$ or $0^{\circ}-10^{\circ}$ gives similar results. Isotropic echo-power level is estimated as the median of each horizontal map (with $0.5 \mathrm{~dB}$ subtracted for Figs. 2e and f, so echo-power tilt tends more smoothly to zero for nearly isotropic conditions, where tilt is noisy since random beams have echo power above isotropic level). Echo power maps are linearly interpolated to constant height for each beam without small-angle approximations for Figs. 2e and $\mathrm{f}, 4$, $5 \mathrm{~g}, \mathrm{~h}$ and $\mathrm{k}-\mathrm{n}$. Tilt is defined as positive to west and south (caused by aspect-sensitive layers tilted downward to west and south) to have the same, not opposite sign as $W$ in Figs. 2c and d, 5a-f.

Correlation of $W$ (Figs. 2c and d) to aspect-sensitive tilt (Fig. 2f) has been interpreted as tilted aspect-sensitive scatterers causing a vertical radar beam to point effectively offvertical, measuring a component of horizontal wind, whereas real $W$ is near zero or opposite sign (Larsen and Röttger 1991; Palmer et al. 1998; Kawano et al. 2001). However $W$ agrees in Figs. 2c and d, except for noise caused by weaker signal/noise ratio in Fig. 2d. With increasing offzenith angle of symmetric beams, aspect sensitivity is often less significant for wind measurements, and horizontal gradients of wind field more significant; these effects could counteract so $W$ measured at any zenith angle is consistent yet wrong. However, a simpler explanation is that measured $W$ in Figs. 2c and d is mostly real, with e.g. mountain waves causing both the non-zero $W$ and tilt (Röttger 2000; Worthington et al. 2001)

Figures $2 \mathrm{~g}-\mathrm{p}$ show echo-power imbalances (EPI) from 8 of 23 symmetric beam pairs in Fig. 1. Aspect-sensitive tilt and EPI may be proportional (Hobbs et al. 2000), EPI values for any given tilt angle in Fig. $2 \mathrm{f}$ depending on aspectsensitivity in Fig. 2b. West-east components of tilt and $6^{\circ}$ EPI (Figs. 2f and h) are similar and more correlated to $W$ than south-north components (Figs. 2e and g), consistent with aspect-sensitive layers tilted west-east, and causing EPI also in northwest-southeast and southwest-northeast azimuths (Figs. 2i and j). Similar correlation of $W$ and EPI shown by Worthington (1999a) is for a different location and radar system, suggesting a real radar-atmospheric effect rather than radar problems.

EPI for west-east $10^{\circ}$ beams in Fig. $2 \mathrm{~m}$ is mostly smaller and patchier, compared to smaller zenith angles in 




Fig. 2. Height-time plots of (a) vertical-beam echo power; (b) anisotropy, vertical minus mean $6^{\circ}$ echo power; (c, d) vertical wind measured by vertical and symmetric $10^{\circ}$ beams, $\times$ shows times of radiosondes in Figs. 3a and b; (e, f) tilt of aspect-sensitive echo power from zenith, with positive tilt defined as to (e) south and (f) west; (g-p) echo power imbalances (EPI) between symmetric pairs of radar beams at $2^{\circ}, 6^{\circ}$, $10^{\circ}, 14^{\circ}, 30^{\circ}$ zenith, the hatched pattern in Figs. $2 \mathrm{~b}$, e-p covers radio-frequency interference; (q, s) vectors of (q) horizontal wind and (s) vertical shear of horizontal wind; $(\mathbf{r}, \mathbf{t})$ alignment of horizontal wavevector of mountain waves, using EPI from (i,j) and $(\mathrm{g}, \mathrm{h}), \mathrm{black}$ arrows showing $|W|>0.2 \mathrm{~ms}^{-1}$ and azimuth error $<12^{\circ}$. Identical dotted lines in (a)-(t) show the approximate region of aspect sensitivity in (b), which is the most relevant area in $(\mathrm{e}-\mathrm{m})$.

Figs. $2 \mathrm{~h}-\mathrm{k}$, as expected since aspect sensitivity can be near to isotropic at $10^{\circ}$ zenith. This is consistent with comparisons of $3.6^{\circ}$ and $10.8^{\circ}$ zenith in Hobbs et al. (2000). EPI for west-east $4^{\circ}$ and $8^{\circ}$ beams (not shown) is intermediate to $2^{\circ}$, $6^{\circ}, 10^{\circ}$ in Figs. $2 \mathrm{~h}, \mathrm{k}$ and $\mathrm{m}$.

At larger zenith angles (Figs. $2 \mathrm{n}$ and $\mathrm{p}$ ) there is a different pattern, explainable by horizontal variability of isotropic echo power. For Fig. 2n, west and east echo powers are averages of beams at $14^{\circ}$ zenith and $\pm 15^{\circ}$ azimuth from west and east, to allow an approximate comparison with Figs. 2h,k,m,p. EPI between symmetric $14^{\circ}$ beams in azimuths $\mathrm{W} 15^{\circ} \mathrm{N}-\mathrm{E} 15^{\circ} \mathrm{S}$ and $\mathrm{W} 15^{\circ} \mathrm{S}-\mathrm{E} 15^{\circ} \mathrm{N}$ (not shown) are both similar to their average in Fig. $2 \mathrm{n}$. W1 $15^{\circ} \mathrm{N}$ means an azimuth rotated $15^{\circ}$ toward north from west; $\mathrm{E} 15^{\circ} \mathrm{S}, \mathrm{W} 15^{\circ} \mathrm{S}$ and $\mathrm{E} 15^{\circ} \mathrm{N}$ use similar notation. For symmetric $30^{\circ}$ beams (Fig. 2p), EPI has a similar pattern to Fig. 2n with larger 


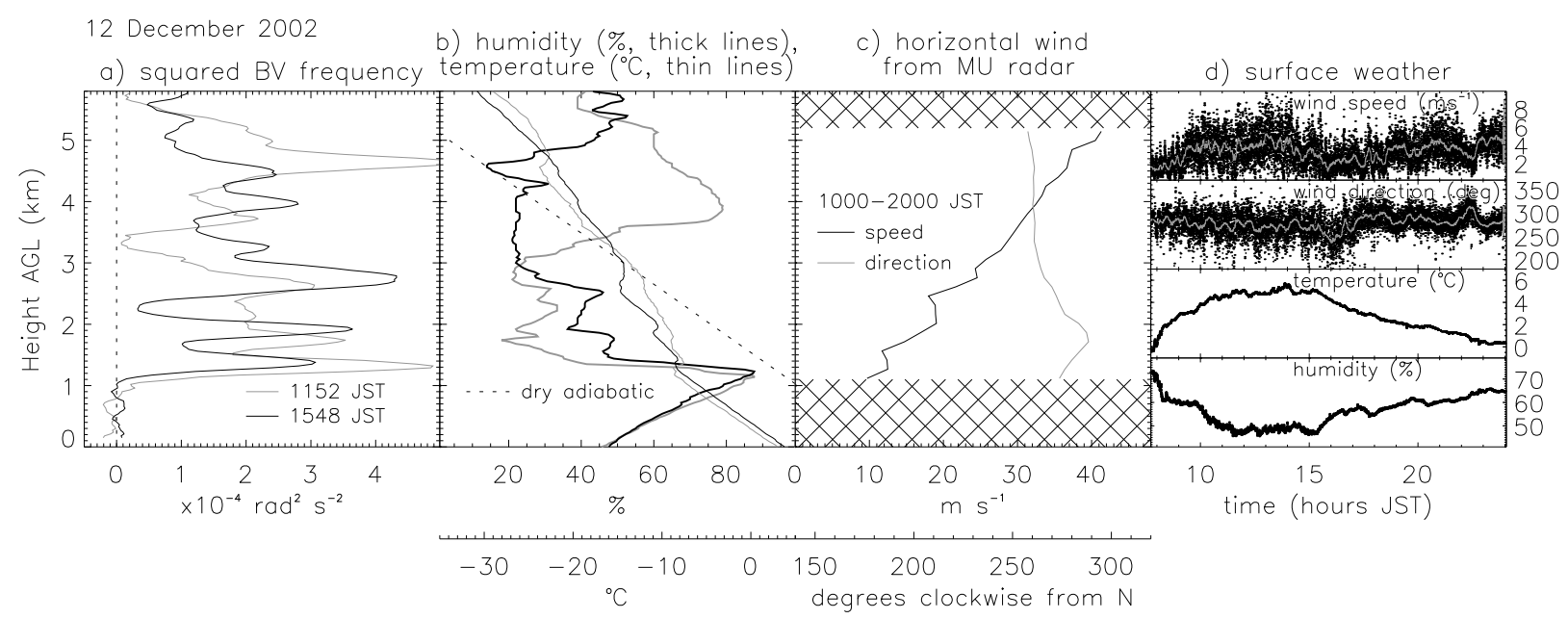

Fig. 3. (a) squared Brunt-Väisälä frequency, (b) relative humidity and temperature from radiosondes launched 1152 and 1548 JST at the MU radar site; (c) horizontal wind speed and direction measured 1000-2000 JST, 1-5 km AGL, by the MU radar; (d) surface weather at the MU radar site; dots are 5-s time averages, with a 10-min running median overplotted of horizontal wind speed and direction.

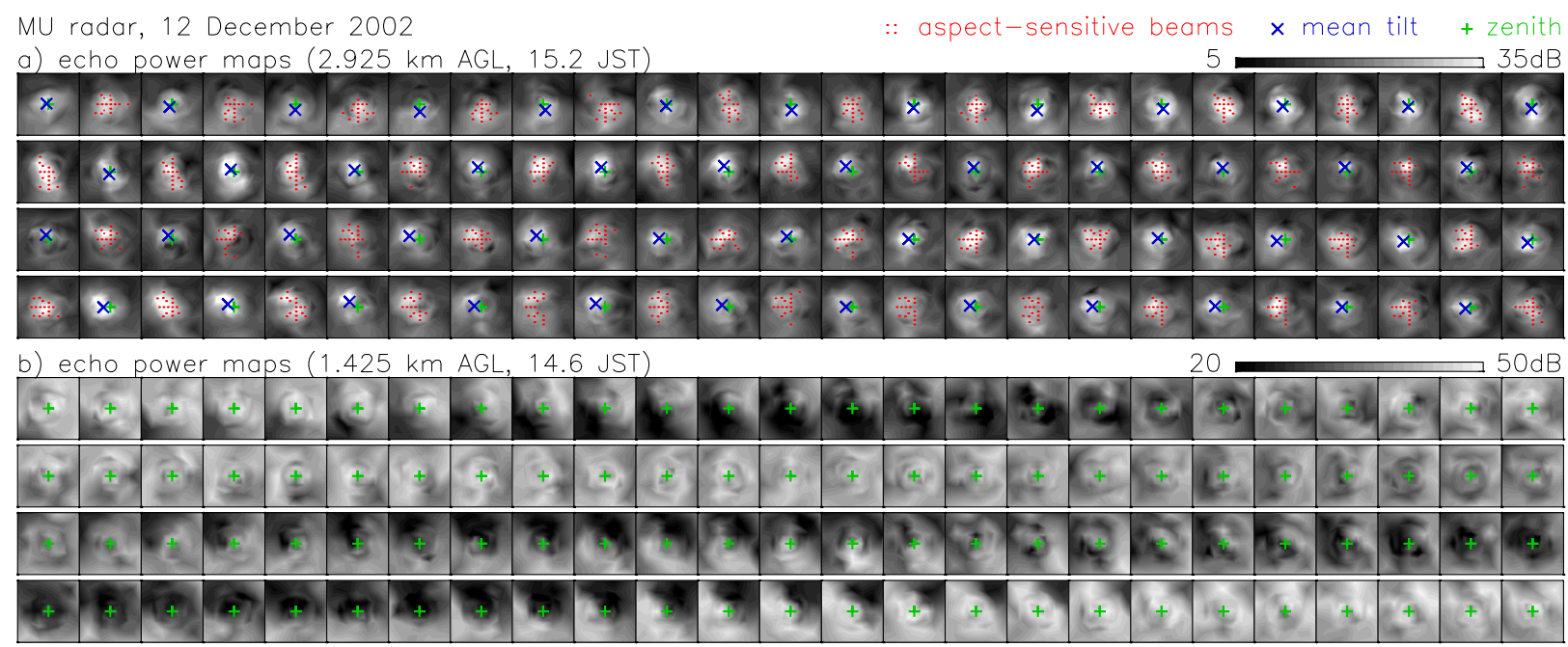

Fig. 4. Horizontal maps of clear-air echo power at heights of (a) aspect-sensitive and (b) convective echoes. Alternate maps in (a) are overplotted with radar beam directions of increased echo power caused by aspect sensitivity (groups of red dots), and mean echo-power tilt from these beams (blue $\times$ ). Time step is $6.55 \mathrm{~s}$, starting top-left, north is at the top of each plot, zenith is marked as green + , and horizontal width is (a) $1460 \mathrm{~m}$, (b) $710 \mathrm{~m}$.

amplitude. Horizontal separation of $30^{\circ}$ beams is more than their height AGL, which is unusual for MST radar, and nearer to the beam geometry used by e.g. weather radars, where beam tilt is often measured upward from the ground instead of from zenith.

Figures $2 \mathrm{q}$ and $\mathrm{s}$ show horizontal wind and its vertical shear, and Figs. $2 \mathrm{r}$ and $\mathrm{t}$ show mountain-wave alignment from different symmetric pairs of $6^{\circ}$ beams (Figs. $2 \mathrm{~g}-\mathrm{j}$ ) to check their self-consistency, with arrows plotted darker where $|W|>0.2 \mathrm{~m} / \mathrm{s}$ and azimuth error $<12 \mathrm{deg}$ as used in Figs. 5-10 of Worthington (1999b). Mountain-wave alignment is near west, roughly opposite to the background wind, or northwest at 17-20 JST. Time resolution of $2 \mathrm{~h}$ for Figs. $2 \mathrm{r}$ and $t$ is because a few hours is usually necessary for a mountain-wave pattern to shift phase enough, that the resulting variations of $W$ and EPI allow measurement of the wave alignment (Worthington, 1999a).

Time series of $W$, tilt and EPI, Figs. 5a-j, show data in Fig. 2 more quantitatively. Similar $W$ is measured with beams $0^{\circ}-20^{\circ}$ off zenith (except for noise, e.g. 19-20 JST in Fig. 5f), despite the varying relative importance of aspect sensitivity and horizontal separation of beams, as a function of beam zenith angle. $W$ in Figs. 5a-f is measurable in both isotropic and aspect-sensitive conditions (Fig. 2b), 
MU radar, 12-13 December 2002

a) vertical wind from vertical beam $\left(\mathrm{m} \mathrm{s}^{-1}\right)$
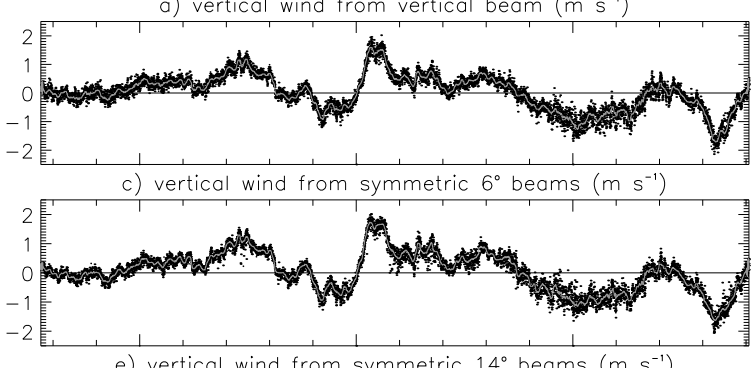

e) vertical wind from symmetric $14^{\circ}$ beams $\left(\mathrm{m} \mathrm{s}^{-1}\right)$

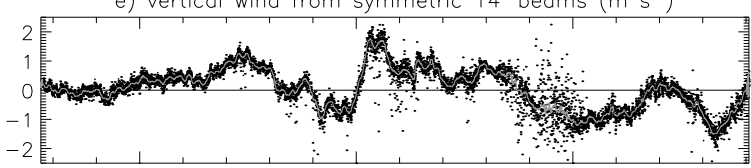

g) tilt south-north (degrees from zenith)
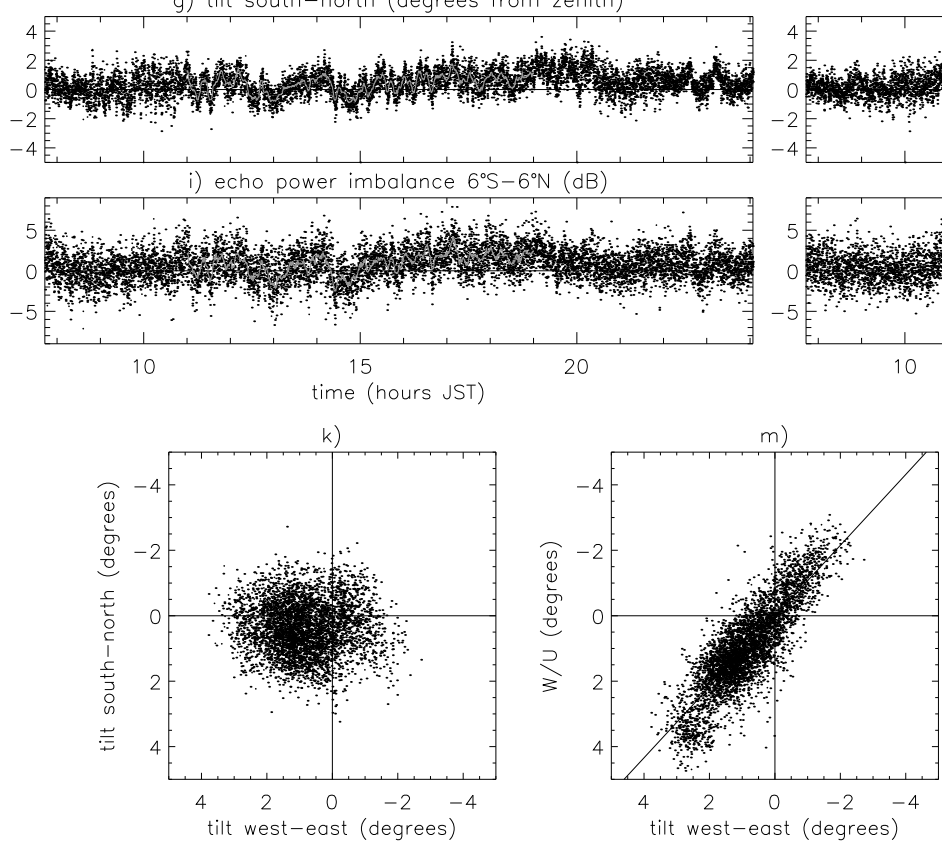

b) vertical wind from symmetric $2^{\circ}$ beams $\left(\mathrm{m} \mathrm{s}^{-1}\right)$

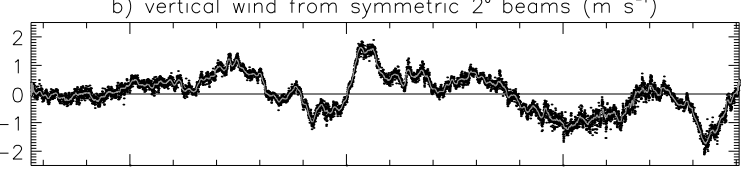

d) vertical wind from symmetric $10^{\circ}$ beams $\left(\mathrm{m} \mathrm{s}^{-1}\right)$

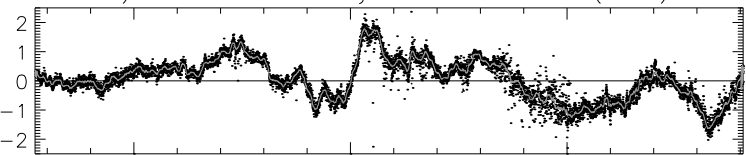

f) vertical wind from symmetric $20^{\circ}$ beams $\left(\mathrm{m} \mathrm{s}^{-1}\right)$

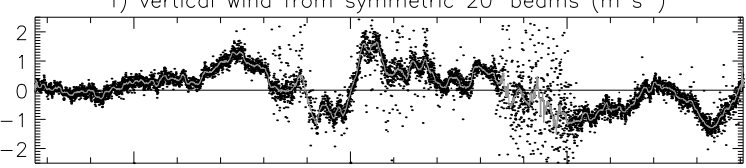

h) tilt west-east (degrees from zenith)
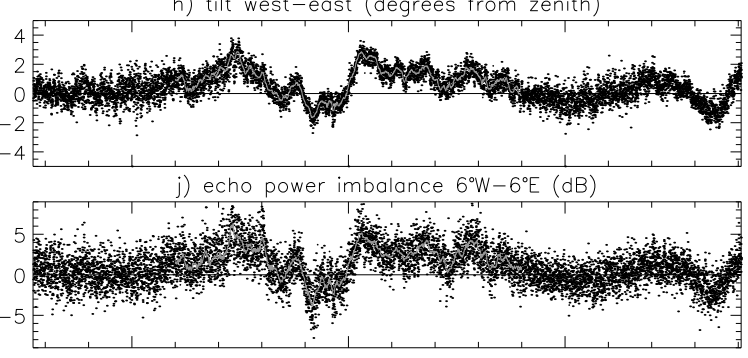

10

time (hours JST)

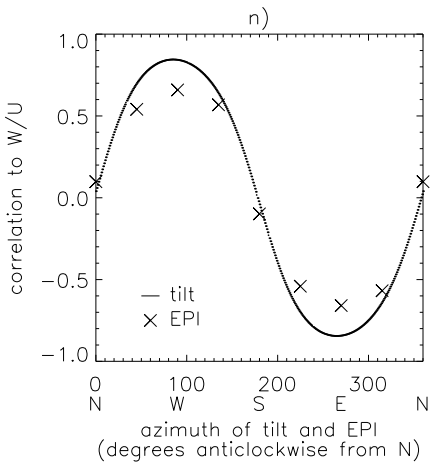

Fig. 5. (a-f) Vertical wind measured by $0^{\circ}, 2^{\circ}, 6^{\circ}, 10^{\circ}, 14^{\circ}$ and $20^{\circ}$ beams; $(\mathbf{g}, \mathbf{h})$ tilt of aspect-sensitive echo power; (i, j) EPI between symmetric beams. (a-j) are averaged $2-4 \mathrm{~km}$ AGL where mountain waves are nearly constant with height in Figs. 2c and d. Measuring time of each dot is $6.55 \mathrm{~s}$, and a 5-min running mean is overplotted; (k) scatterplot of tilts $(\mathrm{g}, \mathrm{h}) ;(\mathbf{m})$ scatterplot of zonal tilt of air flow and aspect-sensitive echo; (n) correlation of $6^{\circ} \mathrm{EPI}$ and aspect-sensitive tilt, as a function of azimuth, to zonal tilt of airflow. (k-n) are for 11-19 JST, when there is aspect-sensitive tilt and EPI.

however tilt is meaningful in aspect-sensitive conditions, approximately within dotted lines in Fig. 2, or for aspect sensitivity more than some value, e.g. $5 \mathrm{~dB}$ (the exact value is arbitrary). Figures $5 \mathrm{~g}, \mathrm{~h}, \mathrm{k}-\mathrm{n}$ use heights with aspectsensitive echo power $>5 \mathrm{~dB}$ above isotropic, since inclusion of isotropic data with zero mean tilt alters the slope of Fig. $2 \mathrm{~m}$, which is used quantitatively to check if air flow and layers are parallel.

Figure 5k shows south-north and west-east tilts from Figs. $5 \mathrm{~g}$ and $\mathrm{h}$ as a scatterplot. Although tilts are more west-east than south-north, there is substantial south-north scatter explainable since mountain-wave patterns vary along horizontal phase lines, e.g. varying wave-cloud thickness in satellite images, or "pile of plates" wave clouds. The $6.55 \mathrm{~s}$ measurement time of each dot is only $\sim 1 \%$ of Brunt-Väisälä period, or $\sim 0.1 \%$ of mountain-wave timescales of hours in Figs. $2 \mathrm{c}$ and d. However, even at $6.55 \mathrm{~s}$ time resolution, west-east tilt of aspect sensitivity shows high correlation to the zonal tilt of air flow (ratio of vertical and zonal wind, $W / U$ ), in Fig. $5 \mathrm{~m}$. Slope near to 1 in Fig. $5 \mathrm{~m}$ implies aspectsensitive scatterers are tilted near parallel to air flow ${ }^{2}$. Figure $5 \mathrm{n}$ shows correlation of zonal air flow tilt to azimuthal

\footnotetext{
${ }^{2}$ In Figs. 3b, 4b, 5b of Worthington et al. (2000), there is +0.25 $\mathrm{ms}^{-1}$ error of radial velocity for all beams, wrongly implying air flow tilted $\sim 0.5^{\circ}$ from horizontal; real $W$ near zero is more consistent with echo power centred near zenith in Fig. $4 \mathrm{a}$.
} 


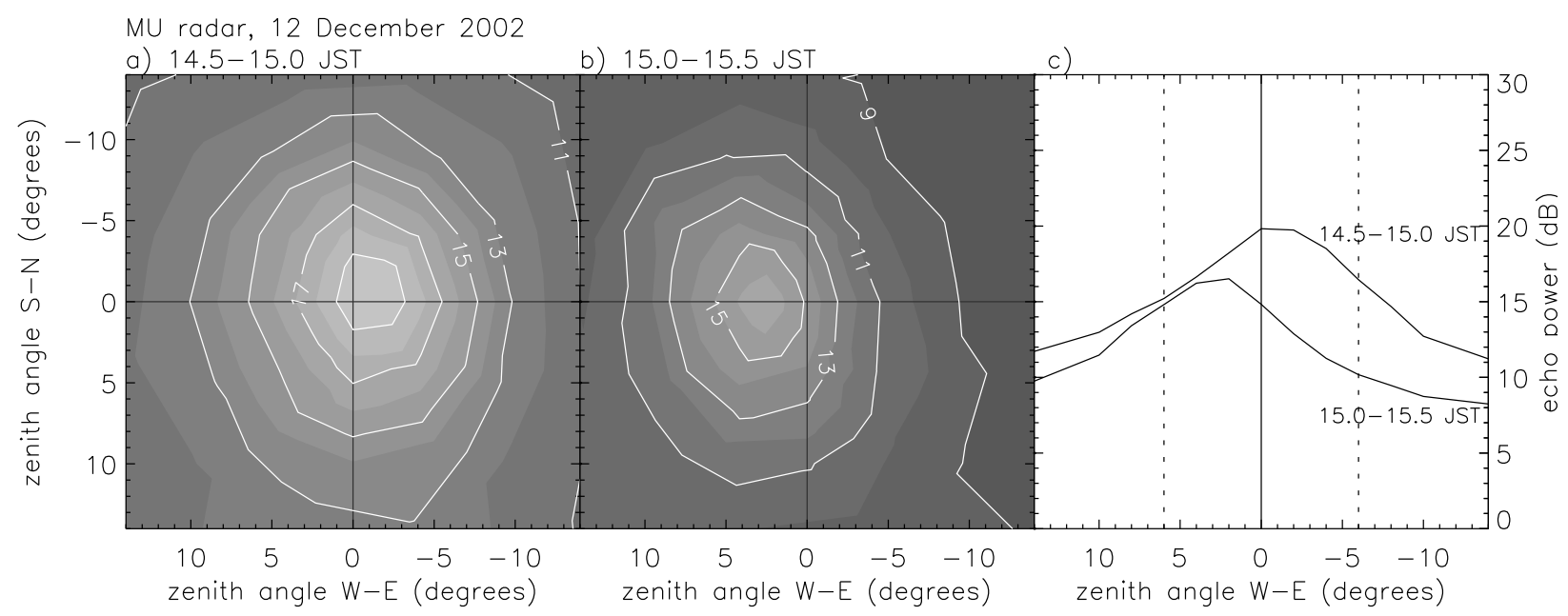

Fig. 6. (a, b) Pair of echo power maps, in $\mathrm{dB}$, their tilt from zenith moving several degrees east to west as mountain waves change phase in Figs. $2 \mathrm{c}$ and $\mathrm{d}$; (c) cross-sections of $(\mathrm{a}, \mathrm{b})$, west-east through zenith, vertical dotted lines showing $6^{\circ}$ zenith used in Figs. $2 \mathrm{r}$ and $\mathrm{t}$. (a-c) are averaged $2-4 \mathrm{~km}$ AGL.

components of tilt and EPI, measured anticlockwise from north for consistency with Figs. 5g-m. Maximum correlation of 0.8 is for approximately west-east tilt as in Fig. $5 \mathrm{~m}$.

Long-term measurements of mountain-wave alignment similar to Figs. $2 \mathrm{r}$ and $\mathrm{t}$ from 5-beam radar (Worthington 1999a,b, 2002) imply mountain waves can be launched slightly above the mountains, with horizontal wavevector aligned parallel to boundary-layer airflow, instead of perpendicular to two-dimensional mountain ridges, and can be similar to convection waves. However, measuring wave alignment uses assumptions, e.g. horizontal wavelength of mountain waves is several times radar beam separation; echo power maps are simply tilted, unmodified, a small angle from zenith in mountain waves; occurrence of aspect sensitivity is independent of mountain-wave properties for smallamplitude waves; and echo power varies on average linearly over small ranges of beam zenith angle.

Röttger (2003, Fig. 2) shows radar beams $23^{\circ}$ off zenith, pointing into different phases of a mountain wave, measuring different wind vectors and tilts. Figures $2 \mathrm{n}$ and $\mathrm{p}$ show effects of such horizontal variability at $14^{\circ}$ and $30^{\circ}$ zenith; however mountain-wave EPI caused by aspect-sensitivity is near zero at these zenith angles. Figures $2 \mathrm{r}$ and $\mathrm{t}$ and Worthington $(1999 \mathrm{a}, \mathrm{b})$ use zenith angle of only $6^{\circ}$, where mountainwave EPI is large amplitude in Figs. $2 \mathrm{~g}-\mathrm{j}$ (due to large echopower gradient with zenith angle, e.g. Fig. 6) and horizontal separation of beams is much less than typical horizontal wavelengths of mountain waves (Worthington, 1999a, Fig. 11). Röttger (2003, Figs. 7 and 8) also suggests scatterer tilt can be unrelated to airflow tilt. For instance, anisotropic turbulence could remain horizontally stratified or tilt parallel to air flow from horizontal. Mountain-wave alignment measurements in Worthington (1999a,b, 2002) are independent of the exact small tilt angle of layers from horizontal, only assuming that layers are tilted in the same azimuth as mountain waves. Nevertheless, Fig. 5m shows almost parallel tilting of layers and airflow from horizontal. A possibility remains of e.g. stratiform cloud layers or temperature inversions already tilted in one azimuth, then tilted also in a different azimuth by mountain waves.

Worthington (1999a) assumes echo power has the same linear dependence on zenith at any azimuth, for aspect sensitivity tilted only a small angle from horizontal. Figure 6 shows a counter-example, with larger tilt $>1^{\circ}$, and echopower gradients different in symmetric $6^{\circ}$ beams, Fig. $6 \mathrm{c}$. However this is consistent with limitations already considered in Worthington (1999a), which although serious for short-term measurements of wave alignment, should produce no long-term rotational bias. Also, short-term measurements are accurate every $45^{\circ}$ by symmetry (Worthington 1999a, Appendix), and show continuity for azimuth resolution less than $45^{\circ}$ (Worthington 1999b, Figs. 6 and 8).

\section{Conclusions}

Volume-imaging radar shows VHF aspect-sensitive echoes tilted in air flow through mountain waves. Vertical wind measurements from beams $0^{\circ}-20^{\circ}$ off zenith are self-consistent. Aspect-sensitive layers tilted by mountain waves cause echopower imbalances between symmetric beams up to $\sim 10^{\circ}$ off zenith. Thin stable layers are tilted from horizontal approximately parallel to the air flow, as assumed in using 5-beam VHF radar to measure mountain-wave alignment.

Acknowledgements. The author was funded by Japan Society for the Promotion of Science, April 2001-March 2003 at Radio Science Center for Space and Atmosphere (now Research Institute for Sustainable Humanosphere), Kyoto University, Kyoto, Japan.

Topical Editor U.-P. Hoppe thanks two referees for their help in evaluating this paper. 


\section{References}

Gage, K. S., Carter, D. A., and Ecklund, W. L.: The effect of gravity waves on specular echoes observed by the Poker Flat MST radar. Geophys. Res. Lett., 8, 599-602, 1981.

Hirono, M., Luce, H., Yamamoto, M., and Fukao, S.: Horizontal maps of echo power in the lower stratosphere using the MU radar. Ann. Geophys., 22, 717-724, 2004.

Hobbs, B. G., Reid, I. M., and Holdsworth, D. A.: Evidence of tilted layers in angle of arrival and Doppler beam steering power measurements. Radio Sci., 35, 983-997, 2000.

Kawano, N., Luce, H., Yamamoto, M., and Fukao, S.: Tilted atmospheric layer and gravity wave studies by simultaneous DBS/SDI observations with the MU radar during the passage of a trough. Radio Sci., 36, 67-77, 2001.

Larsen, M. F., and Röttger, J.: VHF radar measurements of inbeam incidence angles and associated vertical-beam radial velocity corrections. J. Atmos. Ocean. Technol., 8, 477-490, 1991.

Palmer, R. D., Larsen, M. F., Fukao, S., and Yamamoto, M.: On the relationship between aspect sensitivity and spatial interferometric in-beam incidence angles. J. Atmos. Sol.-Terr. Phys., 60, 37-48, 1998.

Röttger, J.: ST radar observations of atmospheric waves over mountainous areas: a review, Ann. Geophys., 18, 750-765, 2000.

Röttger, J.: The inclination of reflectivity stratifications. Proceedings of the 10th workshop on technical and scientific aspects of MST radar, Piura, Peru, 13-20 May 2003, 306-309, 2003.

Sato, K.: Vertical wind disturbances in the troposphere and lower stratosphere observed by the MU radar. J. Atmos. Sci., 47, $2803-$ 2817,1990

Sato, K.: Vertical wind disturbances in the afternoon of midsummer revealed by the MU radar. Geophys. Res. Lett., 19, 1943-1946, 1992.

Shibagaki, Y., Yamanaka, M. D., Hashiguchi, H., Watanabe, A., Uyeda, H., Maekawa, Y., Fukao, S.: Heirarchical structures of vertical velocity variations and precipitating clouds near the Baiu frontal cyclone center observed by the MU and meteorological radars. J. Meteorol. Soc. Japan., 75, 569-596, 1997.
Starr, J. R. and Browning, K. A.: Observations of lee waves by high-power radar. Q. J. R. Meteorol. Soc., 98, 73-85, 1972.

Takayabu, I., Yamanaka, M. D., and Fukao, S.: A mechanism for the reversal of long-term average vertical velocities around east Asia during the cold season. J. Meteorol. Soc. Japan., 78, 13-23, 2000.

Tsuda, T., Gordon, W. E., and Saito, H.: Azimuth angle variations of specular reflection echoes in the lower atmosphere observed with the MU radar. J. Atmos. Sol.-Terr. Phys., 59, 777784, 1997.

Worthington, R. M.: Calculating the azimuth of mountain waves, using the effect of tilted fine-scale stable layers on VHF radar echoes. Ann. Geophys., 17, 257-272, 1999a.

Worthington, R. M.: Alignment of mountain wave patterns above Wales: A VHF radar study during 1990-1998. J. Geophys. Res., 104, 9199-9212, 1999 b.

Worthington, R. M.: Mountain waves launched by convective activity within the boundary layer above mountains. Boundary-Layer Meteorol., 103, 469-491, 2002.

Worthington, R. M.: All-weather volume imaging of the boundary layer and troposphere using the MU radar. Ann. Geophys., 22, 1407-1419, 2004.

Worthington, R. M. and Thomas, L.: The measurement of gravitywave momentum flux in the lower atmosphere using VHF radar. Radio Sci., 31, 1501-1517, 1996.

Worthington, R. M., Muschinski, A., and Balsley, B. B.: Bias in mean vertical wind measured by VHF radars: Significance of radar location relative to mountains. J. Atmos. Sci., 58, 707-723, 2001.

Worthington, R. M., Palmer, R. D., Fukao, S., Yamamoto, M., and Astin, I.: Rapid variations in echo power maps of VHF radar backscatter from the lower atmosphere. J. Atmos. Sol.Terr. Phys., 62, 573-581, 2000.

Yamamoto, M. K., Fujiwara, M., Horinouchi, T., Hashiguchi, H., and Fukao, S.: Kelvin-Helmholtz instability around the tropical tropopause observed with the Equatorial Atmosphere Radar. Geophys. Res. Lett., 30, 1476, 2003. 